\title{
We used to call them hermaphrodites
}

\author{
Eric Vilain, MD, PhD, ${ }^{1}$ John C. Achermann, $M D, P h D,{ }^{2}$ Erica A. Eugster, $M D,{ }^{3}$ Vincent R. Harley, PhD, ${ }^{4}$ \\ Yves Morel, $M D, P h D,{ }^{5}$ Jean D. Wilson, $P h D^{6}$, and Olaf Hiort, $M D^{7}$
}

Sex is just as complicated as humans are. What seems a rather straightforward concept - with an unequivocal answer to the proverbial delivery room question, "Is it a boy or a girl?"-is in reality full of nuances and complexities, just like any human trait. From a biological standpoint, the appearance of the external genitalia is only one parameter among many, including chromosomal constitution, the sequence of sex-determining genes, gonadal structure, the profile of gonadal hormones, and the internal reproductive structures.

One of the pillars of the modern scientific method is to test models and try to prove them wrong. ${ }^{1}$ However, sex and sexuality have long been an exception to modern standards of science because of the perceived consequences of scientific findings on controversial social debates. Human sexual anatomy was categorized into five types in the 19th century. An individual could be a female or a male (with typical feminine or masculine external genitalia, respectively), a female or male pseudohermaphrodite, or a true hermaphrodite. Male or female pseudohermaphrodite- terms no longer appropriatereferred to individuals with ambiguous external genitalia, a blurring between masculine and feminine features, and the presence of either testes or ovaries. True hermaphrodites have both testicular and ovarian tissue. As noted by Dreger, ${ }^{2}$ this model, centered on the gonadal anatomy, was adopted by clinicians, and all patients born with ambiguous genitalia were traditionally classified into one of these categories. For example, individuals born with Congenital Adrenal Hyperplasia have been categorized as female pseudohermaphrodites.

However, scientific advances of the past half century have shown that this model, taking into consideration exclusively the type of gonads, is inaccurate. The early embryological experiments of Jost in 1947 suggested that sex development can be viewed as a two-phase process: sex determination (the orientation of an originally undifferentiated and bipotential gonad into either testis or ovary) and sex differentiation (the development of external and internal genitalia). It took a little

\footnotetext{
From the ${ }^{1}$ Department of Human Genetics, University of California Los Angeles School of Medicine, Los Angeles, California; ${ }^{2} U C L$ Instistute of Child Health, London, United Kingdom; ${ }^{3}$ Pediatric Endocrinology, Riley Hospital, Indiana University, Indianapolis, Indiana; ${ }^{4}$ Human Molecular Genetics, Prince Henry's Institute of Medical Research, Melbourne, Australia; ${ }^{5}$ Laboratoire de Biochimie Endocrinienne et Moleculaire, Hopital Debrousse, Lyon, France; ${ }^{6}$ University of Texas Southwestern Medical Center, Dallas, Texas; ${ }^{7}$ Department of Pediatrics, Medical University of Lubeck, Lubeck, Germany.

Eric Vilain, MD, PhD, UCLA Department of Human Genetics, 695 Charles Young Drive South, Los Angeles, CA 90095-7088. E-mail: evilain@ucla.edu

Submitted for publication September 8, 2006.

Accepted for publication October 26, 2006.
}

DOI: 10.1097/GIM.0b013e31802cffcf more than 40 years to identify the main molecular trigger of sex determination, the Y-linked, DNA-binding and -bending transcription factor SRY. ${ }^{3,4}$ Mutations in SRY in XY individuals cause gonadal dysgenesis and a female phenotype, providing strong genetic evidence that it is a major sex-determining gene. However, few patients with disorders of sex determination can be explained by mutations in SRY, indicating the existence of other sex-determining genes that have been progressively identified since $1990 .{ }^{5}$ As for sex differentiation, most genes that have been well characterized code either for hormonal biosynthetic enzymes or hormone receptors. The sheer number of genes involved in sex development, the variety of their products, and the diversity of their function has led to the notion of sex as a complex trait in which "molecular sex" influences the various steps of sex determination and sex differentiation.

The spectacular molecular advances in our understanding of sex now warrant a reevaluation of the standard classification, which has become too vague to be efficient for the accurate analysis of outcomes data. From a patient's perspective, the nomenclature has two main issues. One is gender labeling, which is often psychologically harmful to the patient. For instance, a woman with androgen insensitivity syndrome would find herself being called a male pseudohermaphrodite, in complete contradiction to her phenotypic sex and, most probably, gender identity. In addition, inclusion of gender in a diagnostic label increases confusion for the parents and even the medical team at the time of gender assignment decisions. The other issue is the comparison of a patient to a mythological creature. There is something eerie about being called by the name of a monstrous fusion of two divine creatures, Hermes and Aphrodite. The fantasies attached to the word "hermaphrodite" have also given rise to a whole industry catering to individuals with paraphilias, looking for sexual gratification with a mythical image of a Man/Woman.

Why has the gonado-centric model not changed throughout the years? First, it provided an intellectual frame that seemed to function. Even if it was a biased biological view, many disorders could be classified according to this model. Second, it is only relatively recently that the genetic mechanisms of sex development started to be deciphered. More importantly, there was no compelling reason to rapidly change the system. The patients' outcomes were unexplored, and their collective existence was essentially invisible. However, in the early 1990s, patient-based intersex advocacy movements started challenging and questioning physicians and their practices, including the traditional nomenclature.

In October 2005, under the auspices of the Lawson Wilkins Pediatric Endocrine Society (USA) and the European Society 
for Pediatric Endocrinology, an international consensus conference was held in Chicago to review the management of intersex disorders. Fifty international experts and representatives of patient advocacy groups were divided into six working groups (genetics, brain programming, medical management, surgical management, psychosocial management, and outcome data), which eventually all agreed on a consensus statement. ${ }^{6}$

The authors (the genetics group) were charged with translating genetic advances into the care of intersex patients. We rapidly realized that the first step of this task was to update the nomenclature of intersexuality. The following principles for the establishment of a new nomenclature were adopted.

First, although a modern categorization should integrate the important progress in molecular genetic aspects of sex determination and differentiation, it should not overemphasize one particular aspect of the biology of sex (for instance, gonadal sex) and should accommodate the spectrum of phenotypic variations. Second, terms should be as precise as possible and should reflect the genetic etiology when available. Finally, the new nomenclature should be understandable by patients and families and should be psychologically sensitive. In particular, gender labeling in the diagnosis should be avoided, and use of the words "hermaphrodite," "pseudohermaphrodite," and "intersex" should be abandoned, as they either are confusing or have a negative social connotation that may be perceived as harmful by some patients and parents.

The term "disorders of sex development" (DSD) was proposed and was defined as "congenital conditions in which development of chromosomal, gonadal, or anatomic sex is atypical." Many changes in terminology were also suggested, which were consistent with our nomenclature principles. ${ }^{6,7}$ The change of nomenclature was unanimously accepted by the large panel of experts present at the consensus conference, who were from very diverse backgrounds (Europe, the Americas, Australia, Asia) and perspectives (surgeons, endocrinologists, psychologists, geneticists, pediatricians).

This change has practical, scientific, and symbolic consequences.

Most importantly, patients will not be labeled with confusing names. But this change will go far beyond the doctor's office. Instead of being pervasively labeled with an all-encompassing term, such as "pseudohermaphrodite," individuals with DSD, just like any patient, will be human beings with a diagnosis.

The medical implication of the new nomenclature will likely be significant. The design of outcome studies will have to incorporate precise diagnostic terms, which will therefore force investigators to systematically categorize patients rather than lumping them. Likewise, by highlighting the fact that the cause of many DSDs remains unknown, the new nomenclature will spur research efforts aimed at elucidating the molecular etiology of specific disorders. As a result, biological science will ultimately influence clinical practice, even in this controversial field. The most interesting consequence to observe will be on the intersex movement itself. Some may believe that it is time to think of DSD in the same framework as asthma or short stature; that is, as conditions that are far from defining individuals. Others may continue to vindicate a distinct cultural identity, perhaps as a means of facing social ostracism and inequality regarding the right to marry or to adopt. Yet, in the latter case, they will identify as intersex on their own terms, not on the terms imposed by the medical system. The advent of a new nomenclature may symbolically mark the beginning of the end of traditional intersex activism, which has had as its main modus operandi a direct confrontation of the medical establishment. It marks a new phase of the advocacy movement, which will now take a more prominent role in educating physicians and parents and supporting patients. Ironically, the historically most influential advocacy group, the Intersex Society of North America, may eventually have to change its name.

The change in nomenclature may seem a slight alteration of the clinical management of disorders of sex development, as the most contentious issue of genital surgery is far from being resolved. However, this change is a gentle revolution that is likely to shift the rapport between health care providers and patients and to help to foster what has been needed the most in this field: dialogue.

\section{References}

1. Popper KR. The logic of scientific discovery. London: Hutchinson Education, 1959.

2. Dreger AD, Chase C, Sousa A, Gruppuso PA, Frader J. Changing the nomenclature/ taxonomy for intersex: a scientific and clinical rationale. J Pediatr Endocrinol Metab 2005; 18:729-733.

3. Sinclair AH, Berta P, Palmer MS, Hawkins JR, Griffiths BL, Smith MJ, et al. A gene from the human sex-determining region encodes a protein with homology to a conserved DNA-binding motif. Nature 1990;346:240-244.

4. Harley VR, Jackson DI, Hextall PJ, Hawkins JR, Berkovitz GD, Sockanathan S, et al. DNA binding activity of recombinant SRY from normal males and XY females. Science 1992;255:453-456.

5. Fleming A, Vilain E. The endless quest for sex determination genes. Clin Genet 2005; 67:15-25.

6. Hughes IA, Houk C, Ahmed SF, Lee PA, and LWPES/ESPE Consensus Group. Consensus statement on management of intersex disorders. Arch Child Dis 2006; 91:554-563.

7. Hughes IA, Houk C, Ahmed SF, Lee PA, Writing Committee for the International Intersex Consensus Conference Participants. Summary of consensus statement on management of intersex disorders. Pediatrics 2006;118:753-757. 